\title{
An Advice System for Consumer's Law Disputes
}

\author{
Nuno Costa ${ }^{1}$, Davide Carneiro ${ }^{1}$, Paulo Novais ${ }^{1}$, Diovana Barbieri ${ }^{2}$, \\ Francisco Andrade ${ }^{3}$ \\ ${ }^{1}$ Department of Informatics, University of Minho, Braga, Portugal \\ nuno.costa.78@gmail.com, \{dcarneiro,pjon\}@di.uminho.pt \\ ${ }^{2}$ Faculty of Law, Salamanca University, Salamanca, Spain \\ diovanabarbieri@usal.es \\ ${ }^{3}$ Law School, University of Minho, Braga, Portugal \\ fandrade@direito.uminho.pt
}

\begin{abstract}
The development of electronic commerce in the last years results in a new type of trade which the traditional legal systems are not ready to deal with. Moreover, the number of consumer claims increased mainly due to the increase in B2C relations and many of these are not getting a satisfactory response. Having this in mind, together with the slowness of the judicial system and the cost/beneficial relation in legal procedures, there is the need for new suited and effective approaches. In this paper we use Information Technologies and Artificial Intelligence to point out to an alternative way of solving these conflicts online. The work described in this paper results in a consumer advice system aimed at fastening and making easier the conflict resolution process, both for consumers and for legal experts.
\end{abstract}

Keywords: Alternative Dispute Resolution, Online Dispute Resolution, Multiagent Systems.

\section{Introduction}

Due to new and emerging technologies the world is in constant evolution, an evolution that is faster each year. This brings along, as one of the many consequences, a whole new way of doing business. A visible effect is the significant increase in B2C relations, on-line or off-line. Although these are, most of the times, simple processes there are often conflicts. To solve them one may appeal to the courts that, by the growing amount of complaints, start piling the processes, taking a long time to solve them, and resulting in a highly negative cost/beneficial relation in legal procedures. In fact, courts rely on an old paradigm based on paper and in which concepts like nationality or location are of major importance. Given this, there is a challenge that emerges from the new reality in which people located anywhere in the world may enter into almost instantaneous electronic interactions, regardless their location or even their nationality. 
In order to have quicker and more efficient decisions, one must start thinking in alternative conflict resolution methods. Traditional existing alternative methods may include negotiation, mediation or arbitration and already take place away from courts. There is now an urgent need to port these methods from the real to the virtual world in order to make them suited to the new business models, resulting in faster and cheaper processes [1].

\section{Alternatives to Courts}

In most of the countries, litigation in court has some well identified disadvantages. Namely, it is usually characterized as a slow and expensive process. These are the two main factors that keep disputant parties away from courts. However, there are more known disadvantages. The fact that it is a public process, with a high public exposure is also undesirable. In fact parties generally like to maintain the privacy about all the aspects of the process, which is not always possible in litigations in court. Another major disadvantage is that the parties have an inferior role on the definition of the outcome. Indeed, the outcome is decided by a judge without an intervention of the parties: what the judge decides is the final outcome, regardless of the opinion or satisfaction of the parties. The fact that the judge is pointed out instead of being agreed on by the parties is also a disadvantage: when parties select and agree on a $3^{\text {rd }}$ party for solving the dispute they are establishing the first point of agreement and taking the first step for a mutually satisfactory outcome.

In the search for efficient and valid alternatives to traditional litigation in courts that could attenuate the mentioned disadvantages two main trends have emerged: Alternative Dispute Resolution (ADR) and Online Dispute Resolution (ODR). ADR includes methods such as mediation, negotiation or arbitration that basically aim at putting the parties into contact, establishing points of agreement and peacefully solving the conflict away from the courts. ODR, on the other hand, aims not only at using such methods in virtual environments but also at the development of technology-enabled tools that can improve the work of legal practitioners and the role of the parties in the whole process.

\subsection{Alternative Dispute Resolution}

Several methods of ADR may be considered, "from negotiation and mediation to modified arbitration or modified jury proceedings" [2]. In a negotiation process the two parties meet each other and try to obtain an agreement by conversation and tradeoffs, having in common the willing to peacefully solve the conflict. It is a non-binding process, i.e. the parties are not obliged to accept the outcome. In a mediation process the parties are guided by a third neutral party, chosen by both, that acts as an intermediate in the dispute resolution process. As in negotiation, it is not a binding process. At last, the arbitration process, which is the one most similar to litigation. In arbitration, a third, independent party, hears the parties and, without their intervention decrees a binding outcome. Although ADR methods represent an important step to keep these processes away from courts, there is still the need for a physical location in 
which the parties meet, which may sometimes be impracticable, in the not so uncommon situations in which parties are from different and geographically distant countries. A new approach is therefore needed, one that uses the advantages of already traditional ADR methods and, at the same time, relies on the information technologies for bringing the parties closer together, even in a virtual way.

\subsection{Online Dispute Resolution}

ODR uses new information technologies like instant messaging, email, videoconference, forums, and others to put parties into contact, allowing them to communicate from virtually anywhere in the world.

The most basic settings of ODR systems include legal knowledge based systems acting as simple tools to provide legal advice, systems that try to put the parties into contact and also "systems that (help) settle disputes in an online environment" [3].

However, these rather basic systems can be extended, namely with insights from the fields of Artificial Intelligence, specifically agent-based technologies and all the well known advantages that they bring along. A platform incorporating such concepts will no longer be a passive platform that simply concerns about putting the parties into contact [4]. Instead, it will start to be a dynamic platform that embodies the fears and desires of the parties, accordingly adapts to them, provides useful information on time, suggests strategies and plans of action and estimates the possible outcomes and their respective consequences. It is no longer a mere tool that assists the parties but one that has a proactive role on the outcome of the process. This approach is clearly close to the second generation ODR envisioned by Chiti and Peruginelli as it addresses the three characteristic enumerated in [4]: (1) the aim of such platform does not end by putting the parties into contact but consists in proposing solutions for solving the disputes; (2) the human intervention is reduced and (3) these systems act as autonomous agents. The development of Second Generation ODR, in which an ODR platform might act "as an autonomous agent" [4] is indeed an appealing way for solving disputes.

ODR is therefore more than simply representing facts and events; a utile software agent that performs useful actions, also needs to know the terms of the dispute and the rights or wrongs of the parties [4]. Thus, software agents have to understand law and/or and processes of legal reasoning and their eventual legal responsibility [5].

This kind of ODR environment thus goes much further than just transposing ADR ideas into virtual environments; it should actually be "guided by judicial reasoning", getting disputants "to arrive at outcomes in line with those a judge would reach" [6]. Although there are well known difficulties to overcome at this level, the use of software agents as decision support systems points out to the usefulness of following this path.

\section{UMCourt: The Consumer Case Law Study}

UMCourt is being developed at University of Minho in the context of the TIARAC project (Telematics and Artificial Intelligence in Alternative Conflict Resolution). The 
main objective of this project is to analyze the role that AI techniques, and more particularly agent-based techniques, can play in the domain of Online Dispute Resolution, with the aim of making it a faster, simpler and efficient process for the parties. In that sense, UMCourt results in an architecture upon which ODR-oriented services may be implemented, using as support the tools being developed in the context of this project. These tools include a growing database of past legal cases that can be retrieved and analyzed, a well defined structure for the representation of these cases and the extraction of information, a well defined formal model of the dispute resolution process organized into phases, among others.

The tools mentioned are being applied in case studies in the most different legal domains, ranging from divorce cases to labor law. In this paper, we present the work done to develop an instance of UMCourt to the specific domain of the consumer law. As we will see ahead, the distributed and expansible nature of our agent-based architecture is the key factor for being able to develop these extensions, taking as a common starting point the core agents developed.

In a few words, the consumer law process goes as follows. The first party, usually the buyer of the product or service, starts the complaint by filling an online form. The data gathered will then be object of analysis by a group of agents that configure an Intelligent System that has a representation of the legal domain being addressed and is able to issue an outcome. At the same time, other agents that make up the core of the platform analyze past similar cases and respective outcomes, that are presented to the user in the form of possible outcomes, so that the user can have a more intuitive picture of what may happen during the process and therefore fight for better outcomes.

At the end, a Human mediator, will verify the proposed solution. He can agree with it or he can change it. In both cases, the agents learn with the human expert. If the expert agrees with the outcome proposed, the agents strengthen the validity of the cases used, otherwise the opposite takes place. This means that the system is able to learn with both correct and incorrect decisions: failure driven learning [7]. The developed system is not to be assumed as a fully automatic system whose decisions are binding but as a decision support system which is aimed at decreasing the human intervention, allowing a better management of the time spent with each case and, nevertheless, still giving the Human the decision making role. The main objective is therefore to create an autonomous system that, based on previous cases and respective solutions, is able to suggest outcomes for new cases.

Among the different law domains that could be object of our work in a project intended to analyze possible ways of solving disputes on-line, we choose consumer law. This choice was made after noticing that consumer claims in Portugal, particularly those related to acquisition of goods or services, are not getting, most times, the solutions decreed in the Portuguese law, undoubtedly due to an unfair access to justice, high costs of judicial litigation versus value of the product/service and the slowness of the judicial procedure. All this generally leads the consumer to give up on the attempt to solve the conflict with the vendor/supplier.

Having all this into consideration, we believe that an agent-based ODR approach, with the characteristics briefly depicted before, is the path to achieve a better, faster and fairer access to justice. 


\subsection{Consumer Law}

As mentioned above, the legal domain of this extension to UMCourt is the Portuguese consumer law. Because this domain is a quite wide one, we restricted it to the problematic of buy and sell of consumer goods and respective warranties contracts. In this field there is a growing amount of conflicts arising between consumers and sellers / providers. In this context, the approach was directed to the modeling of concrete solutions for the conflicts arising from the supply of defective goods (embodied mobiles or real estate).

We also thought relevant to consider financial services as well as the cases in which there are damages arising out of defective products, although this is yet work in progress.

Regarding the boundaries that were established for this extension of UMCourt, we have tried to model the solutions for conflicts as they are depicted in Decree of Law (DL) 67/2003 as published by DL 84/2008 (Portuguese laws).

Based upon the legal concepts of consumer, supplier, consumer good and the concluded legal business, established on the above referred DL and on the Law 24/1996 (Portuguese law), we developed a logical conduct of the prototype, having in view the concrete resolution of the claims presented by the buyer. In this sense, we considered the literal analysis of the law, as well as the current and most followed opinions in both Doctrine and national Jurisprudence.

During the development and assessment of the platform, we realized that the prototype can be useful in cases when the consumer (physical person) [8] is acquiring the good for domestic/private use [9], or is a third acquirer of the good (Law 24/1996, article 2nd nr.1, and DL 67/2003, article 1st B, a) and 4th nr. 6). Besides these cases, it is also usefully applied in situations in which the consumer has celebrated a legal contract of acquisition, buy and sell within taskwork agreement, or renting of embodied mobile good or real estate (DL 67/2003, article 1st A and 1st B, b)).

Still, contracting must take place with a supplier acting within the range of his professional activities, being this one the producer of the good himself, an importer in the European Union, an apparent producer, a representative of the producer or even a seller (Law 24/1996, article 2nd nr. 1 and DL 67/2003, art. 1st B, c), d) and e)). At last, the defect must have been claimed within the delay of warranty (DL 67/2003, articles 5 and 9), and the delay in which the consumer is legally entitled to claim his rights towards the supplier has as well to be respected (DL 67/2003, article 5 A).

Once the legal requests are fulfilled, the solutions available to the consumer will be: repairing of the good (DL 67/2003, articles 4th and 6th); replacement of the good (DL 67/2003 articles 4th and 6th); reduction of price (DL 67/2003 article 4th); resolution of the contract (DL 67/2003, article 4th) or statement that there are no rights to be claimed by the consumer (DL 67/2003, art. 2nd, nrs. 3 and 4, arts. 5, 5A and 6).

These decrees have been modeled in the form of logic predicates and are part of the knowledge of the software agents, which use these predicates in order to make and justify their decisions. 


\subsection{Architecture}

As stated before, the architecture of UMCourt is an agent-based one. The development of ODR tools that might act "as an autonomous agent" [15] is indeed an appealing way for solving disputes. Such tools imply that agents are able of reading their environment (which comprises the parties, the problem domain and characteristics, the norms and other parameters). Agents also need to have enhanced communication skills that allow them to exchange complex knowledge with both parties. Thus, agents need a knowledge representation mechanism able to store the data gathered during all the phases of the process (which may include data about norms addressed, problem domain, items in dispute, among others). Agents also need advanced cognitive skills for dealing with this information and eventually infer conclusions and propose strategies and advice for the parties. Additionally, agents are a tool suited for addressing some of the new challenges that the legal field is facing.

UMCourt is built on such architecture, as presented in Figure 1 in which a view of the core agents that build the backbone of the architecture is shown. This backbone has as the most notable services the ability to compute the Best and Worst Alternative to a Negotiated Agreement, BATNA and WATNA, respectively [10] and the capacity to present solutions based in the observation of previous cases and their respective outcomes [11].

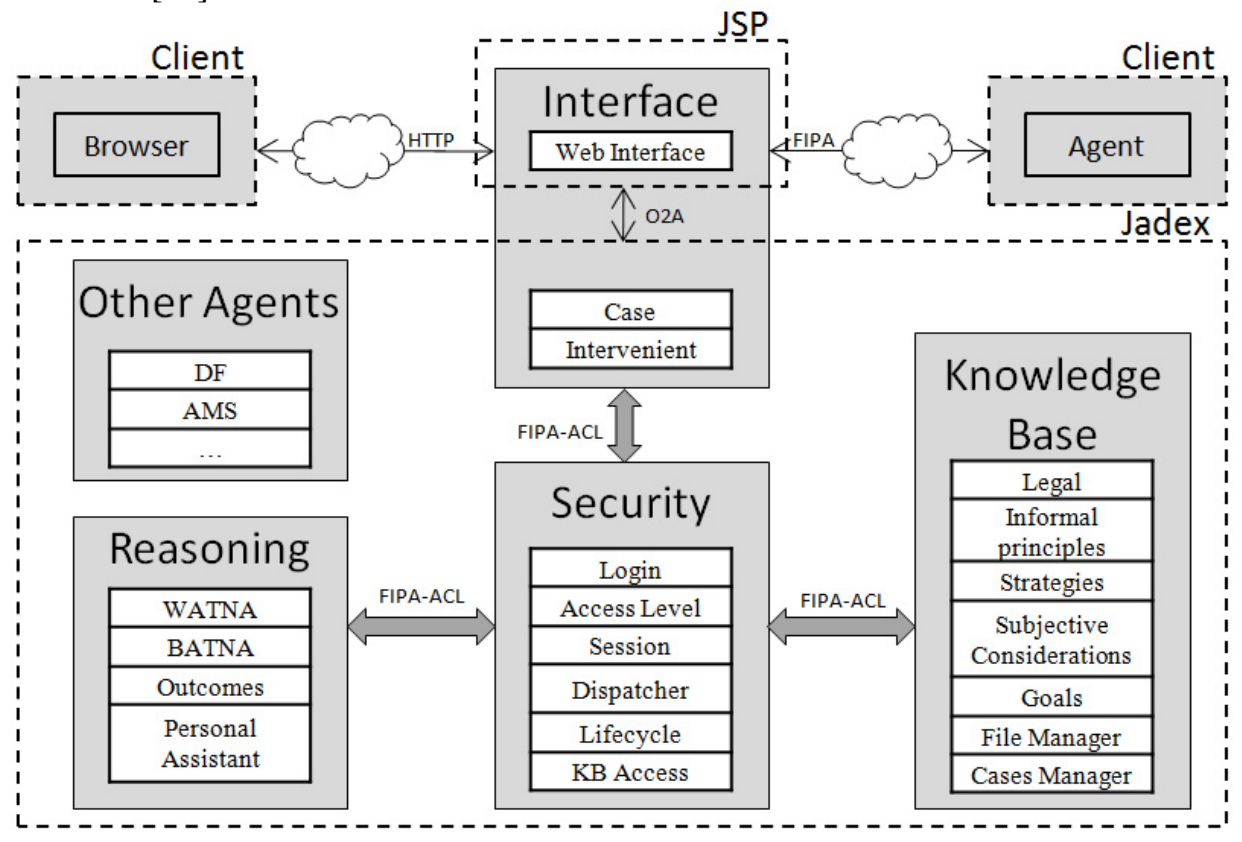

Fig. 1. A simplified vision of the system architecture.

The interaction of the user starts by registering in the platform and consequent authentication. Through the intuitive dynamic interfaces, the user inputs the requested needed information. After submitting the form, the data is immediately available to the agents that store it in appropriate well defined XML files. This data can later be 
used by the agents for the most different tasks: showing it to the user in an intuitive way, automatic generation of legal documents by means of XSL Transformations, generation of possible outcomes, creation of new cases, among others. Alternatively, external agents may interact directly with the platform by using messages that respect the standard defined.

Table 1 shows the four high-level agents and some of their most important roles in the system. To develop the agents we are following the evolutionary development methodology proposed by [12]. We therefore define the high level agents and respective high level roles and interactively break down the agents into more simple ones with more specific roles. The platform, without the extensions, is at this moment constituted by 20 simpler agents. To the agents that make part of the extension we will call from now on extension agents. Between each of these phases tests can be conducted to access the behaviour of the overall system.

Table 1. A description of the high level agents and respective main roles.

\begin{tabular}{|c|c|c|}
\hline $\begin{array}{l}\text { High-level } \\
\text { Agent }\end{array}$ & Description & Main Roles \\
\hline Security & $\begin{array}{l}\text { This agent is responsible for } \\
\text { dealing with all the security } \\
\text { issues of the system }\end{array}$ & $\begin{array}{l}\text { Establish secure sessions with users } \\
\text { Access levels and control } \\
\text { Control the interactions with the knowledge } \\
\text { base } \\
\text { Control the lifecycle of the remaining agents }\end{array}$ \\
\hline $\begin{array}{l}\text { Knowledge } \\
\text { Base }\end{array}$ & $\begin{array}{l}\text { This agent provides methods } \\
\text { for interacting with the } \\
\text { knowledge stored in the } \\
\text { system }\end{array}$ & $\begin{array}{l}\text { Read information from the KB } \\
\text { Store new information in the KB } \\
\text { Support the management of files within the } \\
\text { system }\end{array}$ \\
\hline Reasoning & $\begin{array}{l}\text { This agent embodies the } \\
\text { intelligent mechanisms of the } \\
\text { system }\end{array}$ & $\begin{array}{l}\text { Compute the BATNA and WATNA values } \\
\text { Compute the most significant outcomes and } \\
\text { their respective likeliness } \\
\text { Proactively provide useful information based } \\
\text { on the phase of the dispute resolution } \\
\text { process }\end{array}$ \\
\hline Interface & $\begin{array}{l}\text { This agent is responsible for } \\
\text { establishing the interface } \\
\text { between the system and the } \\
\text { user in an intuitive fashion }\end{array}$ & $\begin{array}{l}\text { Define an intuitive representation of the } \\
\text { information of each process } \\
\text { Provide an intuitive interface for the } \\
\text { interaction of the user with the system } \\
\text { Provide simple and easy access to important } \\
\text { information (e.g. laws) according to the } \\
\text { process domain and phase }\end{array}$ \\
\hline
\end{tabular}

This means that the advantages of choosing an agent-based architecture are present throughout all the development process, allowing us to easily remove, add or replace agents. It also makes it easy to later on add new functionalities to the platform, by simply adding new agents and their corresponding services, without interfering with the already stable services present. This modular nature of the architecture also increases code reuse, making it easier to develop higher level services through the compositionality of smaller ones. The expansibility of the architecture is also increased with the possibility to interact with remote agent platforms as well as to 
develop extensions to the architecture, like the one presented in this paper. We also make use of the considerable amount of open standards and technologies that are nowadays available for the development of agent-based architectures that significantly ease the development, namely FIPA standards and platforms such as Jade or Jadex [14].

\subsection{Data Flow in the System}

All the modules that integrate the system meet the current legislation on Consumer law. When the user fills the form to start a complaint, he indicates the type of good acquired, the date of delivery and the date of defective good denunciation, stipulating also the date when the good was delivered to repair and/or substitution. He can also indicate the period of extrajudicial conflict resolution attempt, if necessary. To justify these dates the user has to present evidence, in general, the issued invoices, by uploading them in digital format. Concerning the defective good, he must indicate its specification and the probable defect causes. At last, he has to identify the supplier type as being a producer or a seller. After filled, the form is submitted. Figure 5 shows a screenshot of the online form.

When the form is submitted, a group of actions is triggered with the objective of storing the information in appropriate well defined structures (Figure 2 and 3). As mentioned before, these structures are XML files that are validated against XML Schemas in order to maintain the integrity of the data. All these files are automatically created by the software agents when the data is filled. The extension agent responsible for performing these operations is the agent Cases.

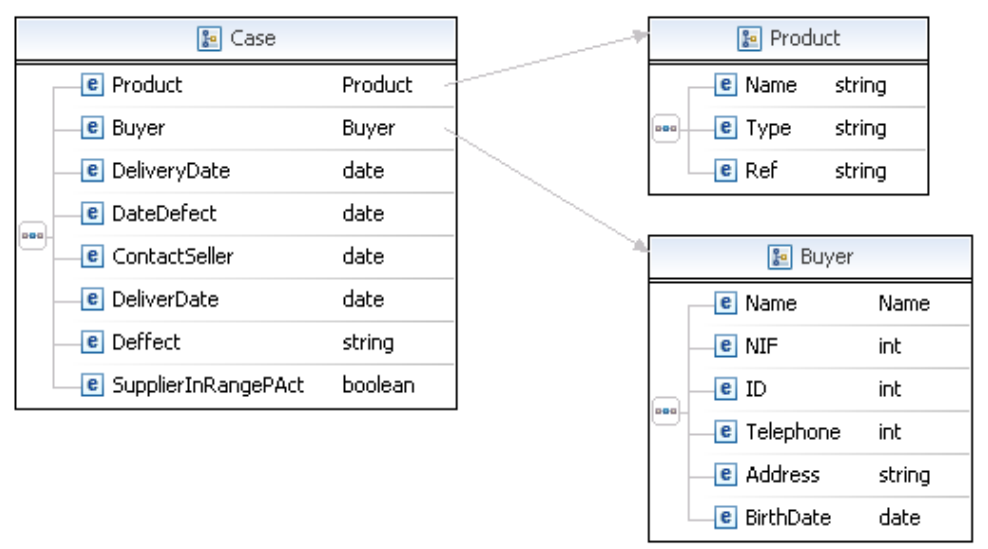

Fig. 2. Representation of the structure of tables that stores the information of each case.

After all the important information is filled in and when a solution is requested, these and other agents interact. Agents BATNA and WATNA are started after all the information is provided by the parties through the interface (Figure 5). These agents then interact with the extension agents Cases and Laws in order to retrieve the 
significant information of the case and the necessary laws to determine the best and worst scenarios that could occur if the negotiation failed and litigations was necessary. Agent Outcomes interacts with extension agent Cases in order to request all the necessary information in order to retrieve the most similar cases.

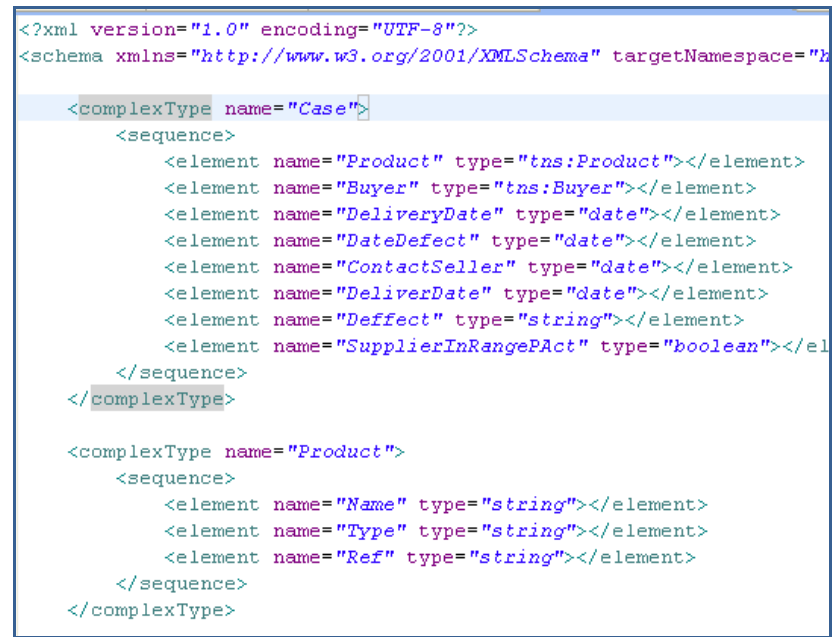

Fig. 3. Excerpts from a XML Schema file of a case.

All this information (WATNA, BATNA and possible outcomes) is then presented to the user in a graphical way so that it may be more intuitively perceived (Figure 4). In that sense, the likeliness is represented by the colored curves which denote the area in which the cases are more likely to occur. A higher likeliness is denoted by a line that is more distant from the axis. To determine this likeliness, the amount of cases in the region is used, as well as the type of case (e.g. binding or persuasive precedent, decisions of higher or lower court) and even if there are groups of cases instead of single cases, as sometimes highly similar cases are grouped to increase the efficiency.

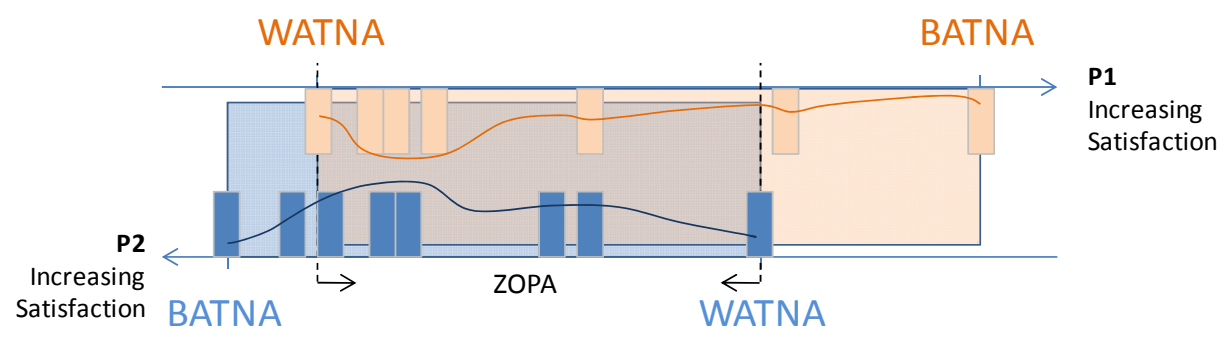

Fig. 4. The graphical representation of the possible outcomes for each party.

The graphical representation also shows the range of possible outcomes for each of the parties in the form of the two big colored rectangles and the result of its intersection, the ZOPA - Zone of Potential Agreement [13], another very important concept that allows the parties to see between which limits is an agreement possible. The picture also shows each case and its position in the ordered axis of increasing 
satisfaction, in the shape of the smaller rectangles. Looking at this kind of representation of information, the parties are able to see that the cases are more likely to occur for each party when they are in the area where the colored lines are further away from the axis of that party. Therefore, the probable outcome of the dispute will probably be near the area where the two lines are closer.

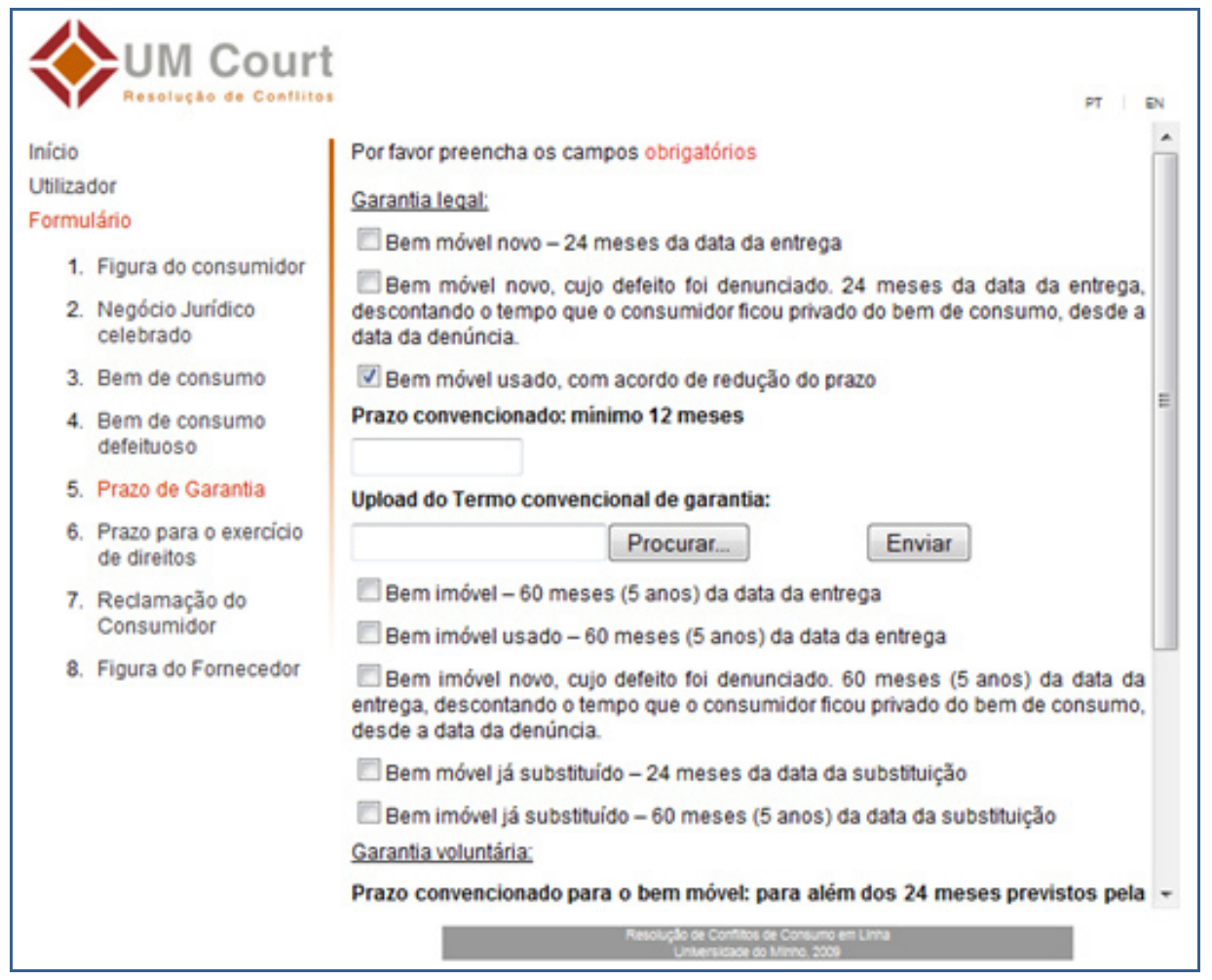

Fig. 5. Screenshot from an online form (in portuguese).

At this point, the user is in a better position to make a decision as he possesses more information, namely important past similar cases that have occurred in the past. In this position the user may engage in conversations with the other party in an attempt to negotiate an outcome, may request an outcome or may advance to litigation, if the WATNA is believed to be better than what could be reached through litigation.

If the user decides to ask the platform for a possible solution, the Reasoning extension agent will contact the extension agents Cases and Laws in order to get the information of the case and the laws that should be applied and will issue an outcome.

The third neutral, when analyzing the outcome suggested, may also interact with these agents, for consulting a specific law or aspect of the case. He analyses all this information, and decides to accept or not to accept the decision of the system. After the solution is verified, it is validated and presented to the user. 


\subsection{Example and Results}

To better expose these processes, let us use as an example a fictitious case (Figure 6): a physical person that acquires an embodied mobile good for domestic/private use. The celebrated legal contract is of the type buy and sell. The date of good delivery is October $22^{\text {nd }}, 2009$. The date at which the consumer found the defect in the good occurred at October $26^{\text {th }}$, 2009 but the good was delivered to repair and/or substitution on October $30^{\text {th }}$, 2009. There was no extrajudicial conflict resolution attempt. As evidence, the user uploaded all invoices relative to the dates mentioned. Concerning the defect that originated the complaint, the user mentioned that the good did not meet the description that was made to him when it was bought. In this case, the supplier acts within the range of his professional activities and he is the producer of the good.

When a solution is requested, the system proceeds to the case analysis and reaches a solution. The good is under the warranty delay: 11 days, calculated through the difference between the date of good delivery and the current date

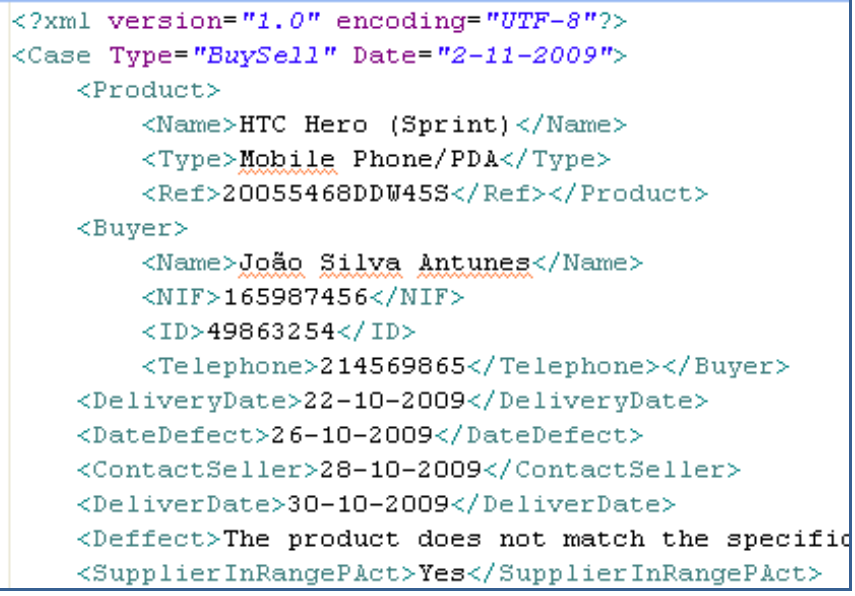

Fig. 6. Excerpt from a fictitious case.

The limit of two months between the date of the defect detection has been respected: 7 days, calculated by the difference between the date of defect finding and the current date. Two years have not passed since the date of denunciation: 2 days, calculated by the difference between the date of denunciation and the current date, deducting the delay which user was deprived of the good because of repair/substitution (since no date of good delivery after repair and/or substitution is declared, the default is the current date). The period of extrajudicial conflict resolution attempt is also deductable, but in this case it doesn't occur. As the good was delivered for repair and/or substitution, the supplier has two choices: either to make the good repair in 30 days (at the maximum) without great inconvenience, and at no cost (travel expenses, man power and material) to the consumer; or to make the good replacement by another equivalent one.

This rather yet simplistic approach is very useful as a first step on the automation of these processes. The case shown here is one of the simplest ones but the operations 
performed significantly ease the work of the law expert, allowing him to worry about higher level tasks while simpler tasks, that can be automated, are performed by autonomous agents.

\section{Conclusions}

In the context of consumer law, only some aspects have been dealt with, still remaining to be modeled: a) the situations covered by the Civil Code, when DL 67/2003 is not to be applied; b) the cases considered in DL 383/89 of damages arising from defective products; and c) the issues of financial services, namely concerning consumer's credit. The work developed until now, however, is already enough assist law experts, enhancing the efficiency of their work.

The next steps are in the sense of further improvements of the agents while at the same time continuing the extension to other aspects of consumer law that have not yet been addressed in this work. Specifically, we will adapt a Case-based Reasoning Model that has already been successfully applied in previous work in order to estimate the outcomes of each case based on past stored cases.

Acknowledgments. The work described in this paper is included in TIARAC Telematics and Artificial Intelligence in Alternative Conflict Resolution Project (PTDC/JUR/71354/2006), which is a research project supported by FCT (Science \& Technology Foundation), Portugal.

\section{References}

1. Klamig, L., Van Veenen, J., Leenes, R.: I want the opposite of what you want: summary of a study on the reduction of fixed-pie perceptions in online negotiations. Expanding the horizons of ODR, Proceedings of the 5th International Workshop on Online Dispute Resolution (ODR Workshop’08), Firenze, Italy pp. 84--94 (2008)

2. Goodman, J.W.: The pros and cons of online dispute resolution: an assessment of cybermediation websites, in Duke Law and Technology Review (2003)

3. De Vries BR., Leenes, R., Zeleznikow, J.: Fundamentals of providing negotiation support online: the need for developing BATNAs. Proceedings of the Second International ODR Workshop, Tilburg, Wolf Legal Publishers pp. 59--67 (2005)

4. Chiti, G., Peruginelli, G.: Artificial intelligence in alternative dispute resolution. Proceedings of LEA, pp. 97--104 (2002)

5. Brazier, T., Jonker, M., Treur, J.: Principles of Compositional Multi-agent System Development. In Proceedings of the 15th IFIP World Computer Congress, WCC98, Conference on Information Technology and Knowledge Systems, pp. 347--360 (1998)

6. Muecke, N., Stranieri, A., Miller, C.: The integration of online dispute resolution and decision support systems. Expanding the horizons of ODR, Proceedings of the 5th International Workshop on Online Dispute Resolution (ODR Workshop'08), Firenze, Italy pp. 62--72 (2008)

7. Leake, D. B.: Case-Based Reasoning: Experiences, Lessons, and Future Directions. AAAI Press (1996) 
8. Almeida, T.: Lei de defesa do consumidor anotada, Instituto do consumidor, Lisboa (in portuguese) (2001)

9. Almeida, C. F.: Direito do Consumo. Almedina. Coimbra (in portuguese) (2005)

10. Notini, J.: Effective Alternatives Analysis in Mediation: "BATNA/WATNA" Analysis Demystified, (http://www.mediate.com/articles/notini1.cfm), 2005. < Last accessed on September, 2010>

11. Andrade, F., Novais, P., Carneiro, D., Zeleznikow, J., Neves, J.: Using BATNAs and WATNAs in Online Dispute Resolution, proceedings of the JURISIN 2009 - Third International Workshop on Juris-informatics, Tokyo, Japan, ISBN 4-915905-38-1, pp. 15-26 (2009)

12. Jennings, N., Faratin, P., Lomuscio, A., Parsons, S., Wooldridge, M., \& Sierra, C.: Automated Negotiation: Prospects, Methods and Challenges. Group Decision and Negotiation, 10(2), pp. 199-215 (2001)

13. Lewicki, R., Saunders, D., Minton, J.: Zone of Potential Agreement, In Negotiation, 3rd Edition. Burr Ridge, IL: Irwin-McGraw Hill (1999)

14. Bellifemine, F., Caire, G., Greenwood, D.: Developing Multi-Agent Systems with JADE, John Wiley \& Sons, Ltd. West Sussex, England (2007)

15. Peruginelli, G., Chiti, G.: Artificial Intelligence in alternative dispute resolution. Proceedings of the Workshop on the law of electronic agents - LEA (2002) 